
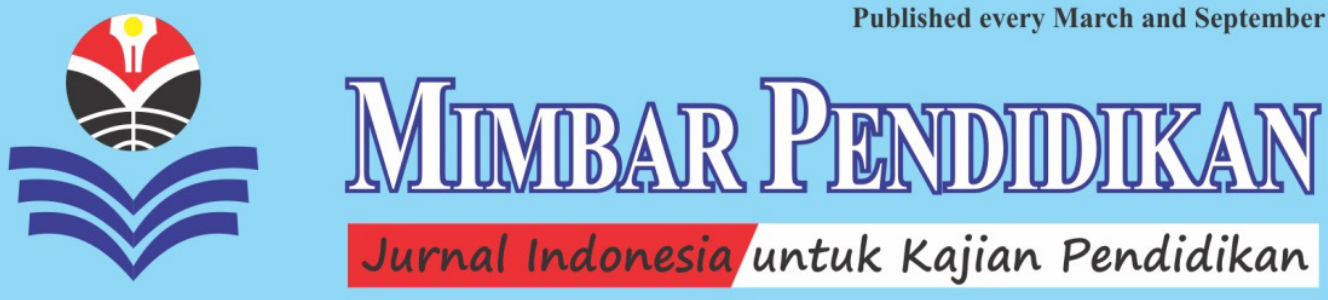

\title{
Aktiviti di Luar Waktu Pengajaran dan Pembelajaran Pendidikan Moral di Malaysia: Satu Pengenalan
}

\begin{abstract}
ABSTRAKSI: Artikel ini mengupas rasional di sebalik pengenalan ALPdP (Aktiviti di Luar waktu Pengajaran dan Pembelajaran) Pendidikan Moral di Malaysia. Seramai tujuh orang peserta kajian, yang terdiri daripada guru Pendidikan Moral daripada enam buah sekolah, telah terlibat secara langsung dalam kajian ini. Kaedah kualitatif dengan menggunakan reka bentuk kajian kes telah digunakan dalam pengumpulan data. Dapatan data bagi kajian ini dikutip melalui temu bual, pemerhatian, dan penelitian dokumen. Dapatan kajian menunjukkan bahawa silibus baharu Pendidikan Moral, iaitu KSSM (Kurikulum Standard Sekolah Menengah), bukan sahaja diajar di dalam kelas malah diselitkan juga dengan pengajaran dan pembelajaran di luar waktu dan dijalankan oleh guru di luar bilik darjah selama 32 jam. ALPdP merupakan komponen baharu dan telah mula dilaksanakan dalam kalangan murid Pendidikan Moral menengah rendah bermula tahun 2017. Penambahbaikan secara berterusan perlu diberi perhatian oleh pihak Kementerian Pendidikan Malaysia agar keberkesanan ALPdP ini dapat dimantapkan dan menjadi proses pengajaran dan pembelajaran yang bermakna kepada murid.

KATA KUNCI: Kurikulum Standard Sekolah Menengah; Aktiviti di Luar Waktu Pengajaran dan Pembelajaran; Pendidikan Moral di Malaysia.
\end{abstract}

ABSTRACT: "Moral Education Activities Beyond Teaching and Learning in Malaysia: An Introduction". This article explores the rationale behind the introduction of TLAOC (Teaching and Learning Activities Outside the Classroom) in Malaysia. A total of seven study participants consisting of Moral Education teachers from six schools were directly involved in this study. Qualitative methods using case study design have been used in data collection. The data obtained for this study were collected through one-to-one interviews, observation, and documents reviews. The results show that the new syllabus of Moral Education, the SCSS (Standard Curriculum for Secondary School), is not only taught in the classroom but is also integrated with teaching and learning outside of the classroom and conducted by teachers for 32 hours. The TLAOC is a new component that has been implemented among lower secondary Moral Education students beginning in 2017. Continuous improvement needs to be given attention by the Ministry of Education Malaysia, so that the effectiveness of TLAOC can be strengthened and become a meaningful teaching and learning process for students.

KEY WORD: Standard Curriculum for Secondary School; Teaching and Learning Activities Outside the Classroom; Moral Education in Malaysia.

About the Austhors: Vijaya Malani Verasamy ialah Pelajar Sarjana (Master) di Jabatan Asas Pendidikan dan Kemanusiaan, Fakulti Pendidikan UM (Universiti Malaya), Kuala Lumpur, Malaysia. Vishalache Balakrishnan, Ph.D. ialah Profesor Madya di Jabatan Asas Pendidikan dan Kemanusiaan, Fakulti Pendidikan UM, Kuala Lumpur, Malaysia. Bagi urusan sebarang akademik, Penulis boleh dihubungi secara terus melalui emel di: vee1810@gmail.com dan visha@um.edu.my

Suggested Citation: Verasamy, Vijaya Malani \& Vishalache Balakrishnan. (2020). "Aktiviti di Luar Waktu Pengajaran dan Pembelajaran Pendidikan Moral di Malaysia: Satu Pengenalan” in MIMBAR PENDIDIKAN: Jurnal Indonesia untuk Kajian Pendidikan, Volume 5(2), September, pp.131-142. Bandung, Indonesia: UPI [Indonesia University of Education] Press, ISSN 2527-3868 (print) and 2503-457X (online).

Article Timeline: Accepted (July 27, 2020); Revised (August 31, 2020); and Published (September 30, 2020). 


\section{PENDAHULUAN}

Sejak zaman pemerintahan British, Pendidikan Moral sentiasa diiktiraf dan diakui dalam kurikulum sekolah Malaysia. Pendidikan Moral telah diajar secara formal di sekolah menengah sejak tahun 1989, dengan menggunakan silibus KBSM atau Kurikulum Bersepadu Sekolah Menengah (KPM, 1996; Sumintono, Tahir \& Rahman, 2012; dan Rahimah, 2015).

Pendidikan Moral di Malaysia merupakan mata pelajaran wajib bagi semua murid bukan Islam, iaitu murid berbangsa China, India, dan lain-lain. Di samping itu, semua murid bukan Islam Tingkatan V wajib menduduki peperiksaan awam SPM (Sijil Pelajaran Malaysia) bagi mata pelajaran Pendidikan Moral bermula tahun 1993 (Basari, 2002; Sumintono, Tahir \& Rahman, 2012; dan KPM, 2017).

Silibus baharu Pendidikan Moral, yang diperkenalkan pada tahun 2017, bermula dengan murid Tingkatan I pada tahun berkenaan. Silibus baharu menampakkan kelainan dalam pelaksanaan pengajaran dan pembelajaran Pendidikan Moral bagi murid Pendidikan Moral menengah rendah, yang berumur di antara 13 hingga 15 tahun. Silibus baharu Pendidikan Moral dikenali sebagai KSSM (Kurikulum Standard Sekolah Menengah), yang menggariskan 96 jam proses pengajaran dan pembelajaran Pendidikan Moral sekolah menengah (Sultoni, 2016; KPM, 2017; dan Isnen, 2019).

Proses pengajaran dan pembelajaran 96 jam Pendidikan Moral ini dibahagikan kepada dua bahagian, iaitu 64 jam pengajaran dan pembelajaran didalam bilik darjah. Seterusnya, 32 jam aktiviti pengajaran dan pembelajaran di luar waktu serta di luar bilik darjah (KPM, 2016a; KPM, 2017; dan Isnen, 2019).

Tumpuan perbincangan dalam artikel ini berfokus kepada 32 jam ALPdP (Aktiviti di Luar waktu Pengajaran dan Pembelajaran) Pendidikan Moral sekolah menengah. Antara cabaran dalam mendidik murid
Pendidikan Moral adalah kepelbagaian masyarakat Malaysia. Guru perlu peka dengan sensitiviti murid yang terdiri daripada pelbagai kaum (Balakrishnan, 2010; Sumintono, Tahir \& Rahman, 2012; dan Hie et al., 2018).

Silibus baharu KSSM telah menggariskan 18 nilai universal dalam ALPdP sebagai saluran pembentukan murid secara holistik. Nilai universal ini dipilih mengikut kesesuaian nilai murni yang diterima umum oleh rakyat Malaysia (Balakrishnan, 2010; Sumintono, Tahir \& Rahman, 2012; dan KPM, 2017).

Kajian ini pula dijalankan kerana terdapat jurang dalam pengajaran dan pembelajaran Pendidikan Moral silibus dahulu, yang memberi penekanan lebih kepada domain kognitif moral berbanding emosi moral dan perlakuan moral. Rasional di sebalik pengenalan silibus baharu, yang memperkenalkan ALPdP dalam Pendidikan Moral bermula tahun 2017, digubal dengan memberikan penekanan sama rata kepada ketiga-tiga domain moral, iaitu kognitif moral, emosi moral, dan perlakuan moral dalam pengajaran dan pembelajaran Pendidikan Moral (KPM, 2017; Hie et al., 2018; dan Isnen, 2019).

Kajian-kajian lepas yang berkaitan dengan ALPdP di dalam dan di luar negara turut didalami dalam kajian ini. Artikel ini akan mengupas secara mendalam rasional pengenalan ALPdP dalam silibus Pendidikan Moral bagi murid sekolah menengah di Malaysia.

Kajian kualitatif dengan menggunakan kaedah kes telah digunakan untuk mengumpulkan data dalam kajian ini. Seramai tujuh orang guru Pendidikan Moral yang mengajar murid Tingkatan I hingga Tingkatan III menjadi peserta kajian ini secara sukarela. Instrumen kajian yang digunakan ialah protokol temu bual, protokol pemerhatian, dan penelitian dokumen. Temu bual semi struktur telah dijalankan oleh penyelidik secara one-to- 
one dengan guru Pendidikan Moral yang mengajar murid Tingkatan I, Tingkatan II, atau Tingkatan III. Pemerhatian pula dilaksanakan oleh penyelidik mengikut ketentuan masa yang ditetapkan oleh guru bersama murid-murid mereka semasa ALPdP (Gay \& Airasian, 2003; Idris, 2010; dan Sidiq, Choiri \& Mujahidin, 2019).

Penyelidik tidak terlibat secara langsung dalam ALPdP yang dijalankan oleh guru agar tidak mengganggu kelangsungan ALPdP. Penelitian dokumen, seperti rancangan harian guru, laporan ALPdP, fail panitia Pendidikan Moral, dan dokumentasi ALPdP turut dijadikan bahan sokongan dalam kajian ini (Neuman, 2006; Hamzah, 2010; dan Hua, 2016).

\section{DAPATAN DAN PERBINCANGAN Rasional Pengenalan ALPdP.}

Pendidikan Moral di Malaysia dirancang selari dengan Falsafah Pendidikan

Kebangsaan, yang menekankan pembentukan murid berakhlak mulia dengan penerapan ketiga-tiga domain moral, iaitu: penaakulan moral, emosi moral, dan perlakuan moral secara seimbang (Sumintono, Tahir \& Rahman, 2012; KPM, 2017; dan Daga, 2020).

Pengenalan 32 jam ALPdP (Aktiviti di Luar waktu Pengajaran dan Pembelajaran) ini telah membantu guru Pendidikan Moral sekolah menengah untuk memberi tumpuan kepada ketiga-tiga domain moral menerusi pelaksanaan ALPdP. Guru mengakui bahawa pelaksanaan ALPdP ini merupakan landasan kepada mereka untuk menerapkan dan memupuk amalan nilai dalam kalangan murid secara langsung menerusi ALPdP (Sumintono, Tahir \& Rahman, 2012; Temu bual dengan Responden A, 9/10/2019; Temu bual dengan Responden C, 17/10/2019; dan Temu bual dengan Responden E, 24/10/2019).

Pelaksanaan ALPdP ini memotivasikan guru untuk sentiasa memberikan penekanan secara sama rata kepada ketiga-tiga domain dalam perancangan ALPdP. Cadangan ALPdP yang digariskan oleh Kementerian Pendidikan Malaysia dalam pelaksanaan ALPdP ialah pembelajaran berasaskan projek, khidmat masyarakat, dan aktiviti lain yang dianggap bersesuaian selari dengan KSSM (Sumintono, Tahir \& Rahman, 2012; KPM, 2016b; dan Daga, 2020).

Hasil dapatan kajian telah menghimpunkan ALPdP yang telah dijalankan oleh guru Pendidikan Moral di sekolah mengikut kesesuaian. Antara ALPdP yang telah dilaksanakan oleh guru Pendidkan Moral ialah aktiviti Urban Farming, lawatan ke rumah orang tua atau warga emas; melukis poster; sukan dan permainan; sambutan hari raya; pidato mengenai isu berkaitan dengan murid; pertandingan melukis kolam sempena sambutan kemerdekaan; membersihkan bilik Pendidikan Moral oleh murid; dan nyayian lagu patriotik sempena sambutan hari kemerdekaan (Mahmood, 2014; Shufiyati, 2016; Temu bual dengan Responden B, 9/10/2019; Temu bual dengan Responden D, 17/10/2019; dan Temu bual dengan Responden F, 24/10/2019).

Aktiviti yang dilaksanakan oleh guru Pendidikan Moral sekolah menengah sememangnya telah dirancang selari dengan pengalaman dan situasi yang dekat dengan murid agar murid dapat mengaplikasikan ketiga-tiga domain moral menerusi ALPdP ini. Pendidikan nilai harus selari dengan dunia nyata. Di samping itu, pengalaman murid penting dalam memastikan kelangsungan pengekalan amalan moral (Mahmood, 2014; Kvamme, 2017; dan Terence \& Kerry, 2018). Lihat gambar 1.

KBAT (Kemahiran Berfikir Aras Tinggi), iaitu kreativiti murid dan kemahiran berkomunikasi, telah ditingkatkan menerusi ALPdP (Aktiviti di Luar waktu Pengajaran dan Pembelajaran). KBAT ialah keupayaan untuk mengaplikasikan pengetahuan, kemahiran, dan nilai dalam membuat penaakulan dan refleksi bagi menyelesaikan 


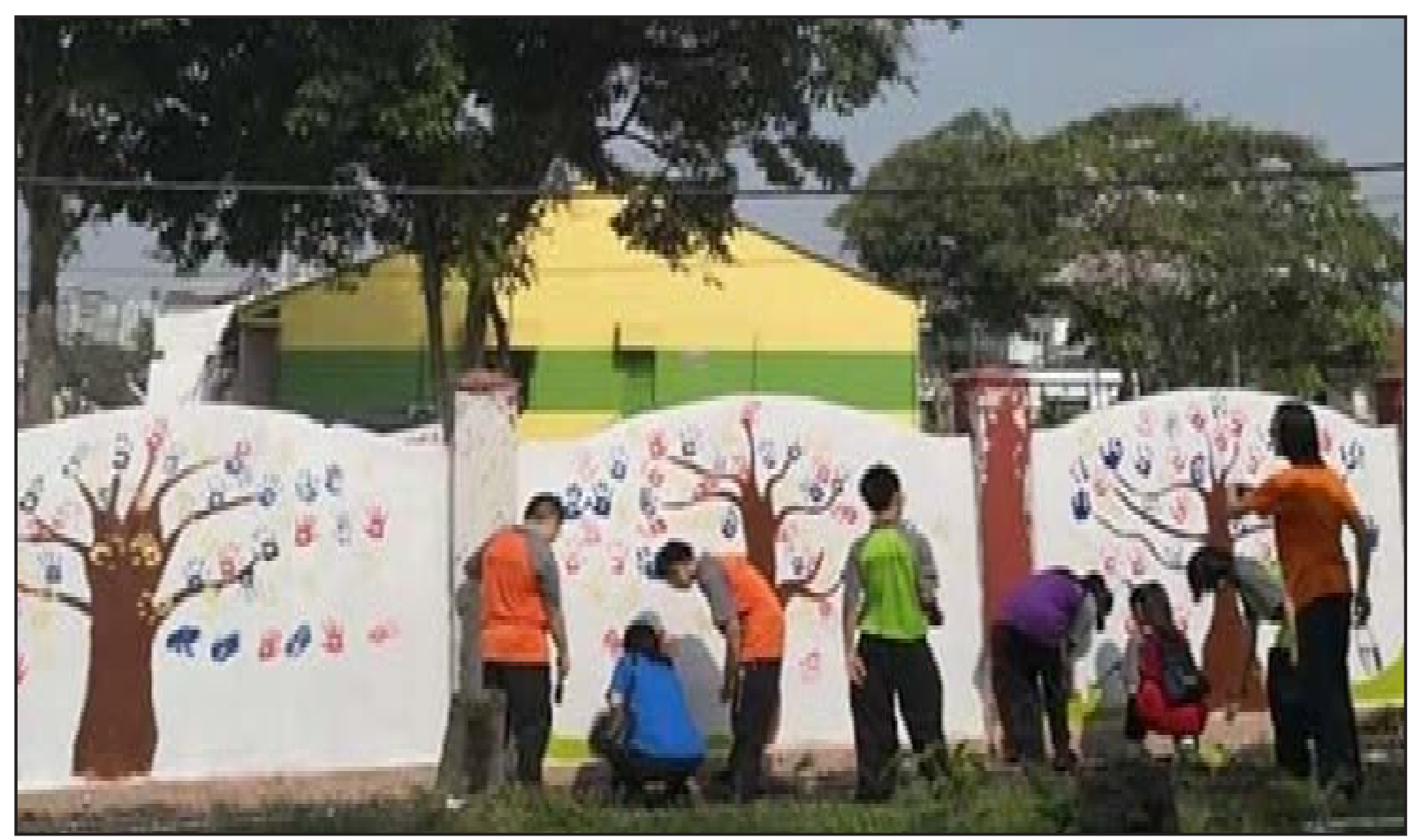

Gambar 1:

Murid sedang Menghasilkan Mural di Sekolah semasa ALPdP (Sumber: Gambar Persendirian)

masalah, membuat keputusan, berinovasi, dan berupaya mencipta sesuatu. KBAT merujuk kepada eleman kemahiran mengaplikasi, menganalisis, menilai, dan mencipta (KPM, 2016b; Vijayaletcmy \& Selvam, 2015; dan Govindarajoo, 2018).

KBAT boleh dilaksanakan di dalam bilik darjah atau di luar bilik darjah. Aktiviti penyelesaian masalah, pembelajaran ikuiri, projek, dan lain-lain dapat meningkatkan amalan berfikir dalam kalangan murid (cf Ismail et al., 2016; KPM, 2016b; dan Govindarajoo, 2018).

Dapatan kajian ini selari dengan kajian M. Rawleigh, H. Kemp \& M. Asfeldt (2019), dan sarjana lainnya, iaitu pendidikan luar kelas mempunyai kesan positif dalam diri murid dengan meningkatkan keyakinan diri, kesedaran diri, kemahiran kepimpinan dan komunikasi, serta memupuk ikatan persahabatan yang kukuh dalam kalangan murid (Awang, Ahmad \& Samad, 2018; Tatang, 2018; dan Rawleigh, Kemp \&
Asfeldt, 2019).

Pelaksanaan ALPdP ini mendedahkan murid dengan situasi yang memerlukan murid untuk bertindak dan menyelesaikan sesuatu isu, dengan mengambil kira persekitaran dan kepentingan bersama. Bukan itu sahaja, malah rangsangan ini membolehkan murid untuk berfikir dan mengambil kira keperluan orang lain dalam menjaga perpaduan. Sekali gus, meningkatkan kemahiran berkomunikasi dalam kalangan murid dalam melaksanakan sesuatu aktiviti (Dewey, 1897; Halim \& Yunus, 2017; dan Temu bual dengan Responden G, 24/10/2019).

Perkara sama turut ditekankan oleh A.L. Mcgowan (2016), dan sarjana lainnya, bahawa pendidikan luar kelas menunjukkan peningkatan dalam kemahiran penyelesaian masalah, kemahiran interpersonal, dan keberkesanan diri dalam kalangan remaja (Yin, 2008; Musa \& Halim, 2015; dan Mcgowan, 2016). Hal ini selari dengan 
dapatan H. Torkos (2019), dan sarjana lainnya, iaitu pembelajaran luar kelas dapat menggalakkan komunikasi antara kumpulan, perkongsian idea dan maklumat, serta autonomi (Abdullah, 2009; Musa \& Halim, 2015; dan Torkos, 2019).

Dapatan kajian B. Christie, S. Beames \& P. Higgins (2016), seiring dengan kajian yang dijalankan oleh A. Lloyd, S. Truong \& T. Gray (2018), dan sarjana lainnya, yang turut menyatakan bahawa pembelajaran luar kelas boleh meningkatkan kreativiti dan imaginasi murid serta menunjukkan peningkatan dalam pencapaian akademik murid. Pembelajaran luar, dengan demikian, mampu memperkaya pengetahuan dan meningkatkan pemikiran kritikal (Musa \& Halim, 2015; Christie, Beames \& Higgins, 2016; Lloyd, Truong \& Gray, 2018; dan Mankiw, Strasser \& Bresson, 2018).

N. Leach (2018), dan sarjana lainnya, turut menyatakan bahawa pembelajaran persekitaran humanistik dapat memupuk hubungan peribadi dalam kalangan guru dan murid, memupuk kolaborasi, kemahiran sosial, kemahiran komunikasi, nilai menghormati, dan pembinaan perwatakan remaja (Ta'rifin, 2009; Leach, 2018; dan Habidin et al., 2019).

Perancangan teliti guru sebelum, semasa, dan selepas pelaksanaan ALPdP ini menjadi salah satu sebab minat murid dalam mata pelajaran Pendidikan Moral telah meningkat. Murid lebih gemar melibatkan diri secara aktif dalam aktiviti yang dirancang oleh guru berbanding hanya

melibatkan diri secara pasif dalam proses pengajaran dan pembelajaran. Pelibatan murid menunjukkan peningkatan melalui aktiviti pembelajaran luar sekolah, kerana aktiviti luar mencetuskan perasaan ingin tahu, meningkatkan minat, dan menyediakan pengalaman yang sukar dilupakan (Sumintono, Tahir \& Rahman, 2012; ClarkeVivier \& Lee, 2018; dan Habidin et al., 2019).

Di samping itu, ALPdP ini memberikan peluang kepada murid untuk melibatkan diri dan menyedari tanggungjawab yang dipikul dalam sesuatu pelaksanaan aktiviti dan komuniti. Pembelajaran luar bilik darjah boleh memberi manfaat dalam pembangunan moral murid. Pendedahan murid dengan ALPdP ini sedikit sebanyak telah menyedarkan murid tentang kepentingan pelibatan secara langsung dalam menyelesaikan sesuatu masalah 
(Sumintono, Tahir \& Rahman, 2012; Thorburn \& Allison, 2017; dan Habidin et al., 2019). Lihat gambar 2.

Pelaksanaan ALPdP (Aktiviti di Luar waktu Pengajaran dan Pembelajaran) ini merupakan aktiviti yang memerlukan perancangan rapi oleh guru Pendidikan Moral, mengikut kreativiti mereka sepenuhnya. Hal ini kerana tiada sebarang modul yang disediakan oleh pihak Kementerian Pendidikan Malaysia dalam pelaksanaan ALPdP ini. Guru perlu merancang dan menjalankan ALPdP yang bersesuaian dengan mengambil kira persekitaran dan keperluan murid agar objektif pembelajaran dapat dicapai oleh guru (Sumintono, Tahir \& Rahman, 2012; Putra, 2017; dan Habidin et al., 2019).

Simon Beames (2010), dan sarjana lainnya, turut menekankan bahawa pelaksanaan pembelajaran bermakna tidak dipengaruhi oleh lokasi atau tenaga pengajar yang terlatih, tetapi perlu menitik-beratkan pelibatan murid agar murid dapat memikul tanggungjawab dan menjalankan aktiviti yang dirancang dengan berkesan. Pengenalan ALPdP ini berfokus kepada proses pembelajaran berpusatkan murid, yang memerlukan murid berfikir, mengambil kira perasaan, dan tindakan yang sewajarnya, tanpa memudaratkan diri sendiri dan orang lain. Oleh itu, guru perlu menyesuaikan diri dengan pelaksanaan ALPdP agar dapat dijalankan dengan berkesan (Sumintono, Tahir \& Rahman, 2012; Abdullah, 2017; dan Awang, Ahmad \& Samad, 2018).

Pendidik pendidikan luar kelas perlu memiliki set kemahiran teknikal, seperti empati, amanah, dan kreativiti. Dalam konteks ini pula, P.E. Chan (2016), dan sarjana lainnya, menyatakan bahawa kesediaan murid untuk mengatasi cabaran, kesediaan murid untuk pembelajaran dan pencapaian akademik, serta tingkah-laku dapat ditingkatkan sekiranya guru komited untuk mewujudkan suasana yang selamat semasa proses pengajaran dan pembelajaran (Chan, 2016; Amatan \& Han, 2019; dan Rawleigh, Kemp \& Asfeldt, 2019).

Pelaksanaan ALPdP yang dikendalikan oleh guru di sekolah menampakkan kesungguhan guru dalam mengaitkan aktiviti dengan pengalaman murid agar dapat mewujudkan pembelajaran yang bermakna dan sebati dalam diri murid. Hal ini selari dengan kenyataan bahawa pembelajaran luar bilik darjah sepatutnya berfungsi sebagai pembelajaran berasaskan pengalaman, yang melibatkan murid secara langsung dan mencabar tahap mental dan sosial, agar situasi ini dapat diharungi dan digunakan sebagai asas untuk tindakan masa hadapan (Sumintono, Tahir \& Rahman, 2012; Eroshkin et al., 2017; dan Arip et al., 2019).

Di samping itu, guru Pendidikan Moral turut memahami bahawa pelaksanaan ALPdP ini memerlukan teknik pengendalian yang berbeza jika dibandingkan dengan proses pengajaran dan pembelajaran di dalam bilik darjah. Dalam konteks ini, K.K. Feille (2017), dan sarjana lainnya, turut menyatakan perkara yang sama bahawa guru memerlukan kemahiran yang berbeza dalam proses pengajaran dan pembelajaran di luar bilik darjah (Sumintono, Tahir \& Rahman, 2012; Feille, 2017; dan Putra, 2017).

\section{Pandemik Covid-19 dan Pendidikan}

Moral. Penularan pandemik COVID-19

(Corona Virus Disease 2019), yang dihadapi oleh masyarakat di seluruh dunia, telah meragut banyak nyawa dan telah menjejaskan pertumbuhan ekonomi dunia. Bukan sahaja ekonomi negara yang terjejas, malah sistem pendidikan turut terkesan berikutan penutupan sekolah sepenuhnya dan penangguhan serta pembatalan peperiksaan awam yang telah dijadualkan pada tahun 2020 (Hasnan, 2020; Jamaludin, 2020; dan WB, 2020).

Situasi tersebut jelas menggambarkan kesan pandemik ini kepada masyarakat. Pelbagai persoalan yang timbul semasa penularan pandemik COVID-19 ini 
terutamanya perkaitan antara pandemik tersebut dengan pengajaran dan pembelajaran Pendidikan Moral, yang telah dilaksanakan di Malaysia sejak tahun 1983 (Sumintono, Tahir \& Rahman, 2012; Sikirit, 2020; Hasnan, 2020; dan Jamaludin, 2020).

Vishalache Balakrishnan (2020), dan sarjana lainnya, menyatakan bahawa pengajaran dan pembelajaran Pendidikan Moral telah melahirkan murid yang mematuhi peraturan pihak berkuasa dan membantu golongan yang memerlukan dengan menyertai aktiviti kesukarelaan semasa pandemik COVID-19. Pada masa yang sama, masih terdapat segelintir murid yang masih tidak akur kepada undang-undang yang ditetapkan oleh pihak berkuasa, manakala kumpulan yang ketiga pula menyebarkan berita palsu mengenai pandemik COVID-19 dan mencetuskan keresahan dalam kalangan masyarakat (Sumintono, Tahir \& Rahman, 2012; Balakrishnan, 2020; dan Nelliani, 2020).

Di samping itu, semasa pandemik COVID-19, kualiti udara di seluruh dunia menampakkan perubahan positif, antaranya di Bangkok, Thailand; New Delhi, India; dan Los Angeles, Amerika Syarikat. Malaysia juga tidak terkecuali dalam hal ini. Kualiti udara di Malaysia turut menampakkan perubahan ketara, apabila peningkatan 14\% kualiti udara baik telah direkodkan sepanjang pandemik COVID-19 dan perintah kawalan pergerakan.

Peningkatan kualiti sungai turut dicatatkan sebanyak $28 \%$ dan berlaku pengurangan dalam kadar pencemaran bunyi juga (Board, 2020; Othman, 2020; dan Teoh, 2020).

Tiga pengajaran yang digariskan untuk membawa perubahan iklim selepas pandemik COVID-19 ialah mengurangkan lengkungan iklim, perubahan sikap dalam kalangan masyarakat, dan menjalani kehidupan dengan batasan. Laporan alam sekitar sepanjang perintah kawalan pergerakan dan pandemik COVID-19 menggambarkan kerakusan manusia terhadap alam sekitar. Manusia sering alpa bahawa alam sekitar, haiwan, dan hidupan lain berkongsi bumi yang sama. Bumi ini bukannya milik manusia sematamata (Lee \& Ong, 2020; Othman, 2020; and dan Teoh, 2020). ${ }^{1}$

Pengajaran dan pembelajaran Pendidikan Moral di Malaysia di bawah silibus baharu iaitu KSSM (Kurikulum Standard Sekolah Menengah) menekankan pelaksanaan ALPdP (Aktiviti di Luar waktu Pengajaran dan Pembelajaran), yang melibatkan pembelajaran aktif, pembelajaran berasaskan projek, dan khidmat masyarakat. Antara aktiviti yang dicadangkan oleh Kementerian Pendidikan Malaysia adalah pameran, teater forum, pertandingan pakaian tradisional, projek lawatan muhibah ke rumah anak yatim, menghasilkan brosur, melaksanakan projek kitar semula, mengutip derma, lawatan sambil belajar ke pusat pemulihan akhlak atau penjara, berpidato, jamuan muhibah, dan projek membantu mangsa pencabulan undang-undang kemanusiaan (Sumintono, Tahir \& Rahman, 2012; KPM, 2016b; dan Balakrishnan, 2020).

Pelaksanaan ALPdP, pada tahun 2019, menampakkan pelbagai cabaran yang dihadapi oleh guru Pendidikan Moral menengah rendah. Antara cabaran yang diketengahkan oleh guru adalah iklim sekolah. Iklim sekolah yang dimaksudkan ialah tenaga pengajar yang terhad menyukarkan guru menjalankan ALPdP dan kekangan dari segi kewangan, memandangkan tiada sebarang peruntukan yang diberikan oleh pihak berkepentingan dalam pelaksanaan ALPdP ini (Johari et al., 2014; Balakrishnan, 2020; dan Temu bual dengan Responden A, 9/10/2019).

Di samping itu, guru turut menyatakan bahawa mereka kurang diberi pendedahan tentang pelaksanaan ALPdP ini; dan kawalan kelas semasa pelaksanaan ALPdP

${ }^{1}$ Lihat juga, contohnya, "Jumlah Kes COVID-19 di Setiap Negeri di Malaysia". Wujud secara online pula di: http://covid-19.moh.gov.my/ [dilayari di Kuala Lumpur, Malaysia: 17hb Julai 2020]. 
ini sukar dikawal. Bukan itu sahaja, malah sikap murid seperti sering tidak hadir ke sekolah, penguasaan bahasa yang lemah, dan kelakuan sambil lewa terhadap mata pelajaran Pendidikan Moral turut memberi impak dalam kelangsungan pelaksanaan ALPdP ini (Sumintono, Tahir \& Rahman, 2012; Balakrishnan, 2020; dan Temu bual dengan Responden C, 17/10/2019).

Meskipun pelaksanaan ALPdP ini telah membuktikan bahawa terdapat kesan positif dalam kalangan murid dari segi penerapan nilai dalam kehidupan seharian, seperti dapat memupuk kesedaran moral dan menerapkan amalan moral. Di samping itu, meningkatkan kemahiran berfikir aras tinggi murid, iaitu kemahiran mencungkil kreativiti murid, mengembangkan kemahiran berkomunikasi, dan meningkatkan inkuiri murid dengan menyemai minat murid terhadap Pendidikan Moral (Shufiyati, 2016; Govindarajoo, 2018; dan Temu bual dengan Responden E, 24/10/2019).

Namun begitu, kerjasama padu daripada guru dan murid amat diperlukan dalam meningkatkan lagi keberkesanan ALPdP ini. Sikap murid semasa pandemik COVID-19 dan perintah kawalan pergerakan sering dikaitkan dengan pengajaran dan pembelajaran Pendidikan Moral dan kesedaran sivik dalam diri mereka (Balakrishnan, 2020; Hasnan, 2020; dan Temu bual dengan Responden G, 24/10/2020).

Oleh itu, guru sebagai agen utama dalam pelaksanaan ALPdP ini perlu kreatif dan kritis bagi memastikan guru dan murid sentiasa berhubung semasa pandemik COVID-19 dan perintah kawalan pergerakan melalui pembelajaran dalam talian. Guru boleh menjalankan ALPdP dalam talian dengan menetapkan tarikh dan masa pelaksanaan aktiviti bersesuaian contohnya aktiviti menanam pokok, pertandingan pakaian tradisional, menzahirkan perasaan tentang keadaan semasa, kepentingan murid memberikan kerjasama sepenuhnya kepada pihak berkuasa dalam menangani penularan Covid-19, dan sebagainya. Sentuhan guru dan kesedaran yang dipupuk penting agar murid dapat memahami keadaan semasa dan bertindak sebagai warganegara bertanggungjawab (Sumintono, Tahir \& Rahman, 2012; Horng et al., 2005; dan Balakrishnan, 2020).

\section{KESIMPULAN}

Matlamat Pendidikan Moral telah dicapai melalui ALPdP (Aktiviti di Luar waktu Pengajaran dan Pembelajaran). Guru Pendidikan Moral mengakui bahawa ALPdP ini menjadi jambatan untuk memupuk amalan nilai dalam kalangan murid. Guru dapat memerhatikan setiap gerak geri murid dan amalan nilai yang dipraktikkan semasa pelaksanaan aktiviti yang melibatkan rakan lain. Oleh itu, tunjang utama Pendidikan Moral iaitu domain moral yang terdiri daripada penaakulan moral, emosi moral, dan perlakuan moral dapat dipupuk dalam diri murid dalam pembentukan murid secara holistik dan berakhlak mulia.

Di samping itu, kemahiran atau bakat yang dimiliki oleh murid dapat dicungkil melalui ALPdP ini. Pelaksanaan ALPdP ini memberi peluang kepada murid untuk memimpin, bekerjasama, dan berkomunikasi bersama rakan dan guru bagi menjayakan sesuatu aktiviti. Pelaksanaan ALPdP ini turut melaporkan kesanggupan murid untuk mengeluarkan duit sendiri bagi menghias kelas dengan bendera Malaysia, sempena sambutan kemerdekaan di peringkat sekolah. Situasi ini sedikit-sebanyak menggambarkan bahawa murid mempunyai semangat patriotik. ALPdP ini mampu meningkatkan amalan nilai dalam kehidupan seharian. Selari dengan kenyataan M. Morris \& L.O. Donnell (2005), murid dapat menghubungkan pengalaman, pengetahuan dan ilmu.

Pelaksanaan ALPdP ini turut melatih guru untuk hanya bertindak sebagai fasilitator dan bukannya agen utama dalam 
pelaksanaan aktiviti yang telah dirancang oleh guru. Fokus utama akan diberikan kepada murid dan pembelajaran adalah berfokus kepada murid sepenuhnya dan guru hanya membantu sekiranya perlu. Pelaksanaan ALPdP ini telah memberi peluang kepada guru untuk berfikir secara kreatif dan kritis untuk merancang ALPdP, yang merangkumi ketiga-tiga domain moral dan selari dengan pengalaman serta bersesuaian dengan murid.

Pendidikan sebenar yang diwujudkan oleh guru ini selari dengan teori learning by doing yang ditekankan oleh John Dewey (1897); manakala teori experiential learning yang disarankan oleh Carl R. Rogers (1951) dengan mewujudkan pengalaman sebenar dan pembelajaran berpusatkan murid diaplikasikan oleh guru dalam pelaksanaan ALPdP ini. Sokongan yang telah diperoleh guru daripada pentadbir sekolah, rakan seperjuangan, dan murid sememangnya sangat membantu dalam memastikan kelangsungan aktiviti ini.

Oleh itu, penambahbaikan secara berterusan perlu diberi perhatian oleh pihak Bahagian Pembangunan Kurikulum, Kementerian Pendidikan Malaysia agar keberkesanan ALPdP ini dapat dimantapkan dan menjadi proses pengajaran dan pembelajaran yang bermakna kepada murid. ${ }^{2}$

\section{Referensi}

Abdullah. (2017). "Pendekatan dan Model Pembelajaran yang Mengaktifkan Siswa" dalam EDURELIGIA, Vol.01, No.01, ms.45-62. Abdullah, Zuraidah. (2009). "Pembentukan Komuniti Pembelajaran Profesional: Kajian

${ }^{2}$ Kenyataan: Kami, yang bertanda tangan di bawah ini, membuat kenyataan sebenar bahawa artikel ini adalah karya akademik kami berdua. Ianya bukan dapatan secara plagiat, memandangkan mana-mana sumber yang kami petik dan rujuk, ianya secara jelas dan penuh tersenarai dalam Referensi atau Bibliografi. Artikel ini pula belum pernah dihantar, sama ada untuk diwasit mahupun untuk diterbit oleh mana-mana jurnal akademik. terhadap Sekolah Menengah di Malaysia” dalam Jurnal Manajemen Pendidikan, Thn.5, No.2

[Oktober]. Wujud secara online pula di: https:// media.neliti.com/media/publications/113604-IDnone.pdf [dilayari di Kuala Lumpur, Malaysia: 24hb Ogos 2019].

Amatan, M.A. \& C.G.K. Han. (2019). "Pengaruh Persekitaran Psikososial Sekolah dan Efikasi Kendiri Guru terhadap Amalan Pengajaran dan Pembelajaran Abad ke-21" dalam International Journal of Education, Psychology, and Counseling, Volume 4(32), ms.301-331. DOI:10.35631/IJEPC.4320027.

Arip, Mohammad Aziz Shah bin Mohamed et al. (2019). "Faktor, Kesan, dan Strategi Menangani Permasalahan Kurang Tumpuan Pelajar Sekolah Menengah didalam Kelas: Suatu Kajian Kualitatif'. Kertas Kerja Tidak Diterbitkan. Tanjung Malim, Perak, Malaysia: Fakulti Pendidikan dan Pembangunan Manusia UPSI [Universiti Pendidikan Sultan Idris].

Awang, Mohd Mahzan, Abdul Razaq Ahmad \& Maizun Samad. (2018). "Penerapan Kemahiran Berfikir Aras Tinggi (KBAT) dalam Pendidikan Sejarah". Kertas Kerja Tidak Diterbitkan. Bangi: FP UKM [Fakulti Pendidikan, Universiti Kebangsaan Malaysia]. Wujud secara online pula di: http://eprints.ulm.ac.id/5478/1/2.\%20 Pendidikan\%20Sejarah [dilayari di Kuala Lumpur, Malaysia: 24hb Ogos 2019].

Balakrishnan, Vishalache. (2010). "The Development of Moral Education in Malaysia" in Asia Pacific Journal of Educators and Education, Volume 25, pp.89-101.

Balakrishnan, Vishalache. (2020). "Good Role Models Needed" in newspaper of New Straits Times. Available online also at: https://www.nst. com.my/opinion/letters/2020/04/580796/goodrole-models-needed [accessed in Kuala Lumpur, Malaysia: 20 May 2020].

Basari, Abd Samad Hasan. (2002). Sistem Penilaian Prestasi Pelajar. Skudai: Penerbit UTM [Universiti Teknologi Malaysia].

Beames, Simon. (2010). "Outdoor Journeys" in Ontario Journal of Outdoor Education, published by the University of Edinburgh.

Board, Jack. (2020). "Bangkok Breaths Cleaner Air during Covid-19 Pandemic and Experts Want it to Last" in Channel News Asia. Available online alsi at: ttps://www.channelnewsasia. com/news/asia/covid-19-thailand-bangkok-airpollution-12674286 [accessed in Kuala Lumpur, Malaysia: 20 May 2020].

Chan, P.E. (2016). "Controlling Setting Events in the Classroom" in Taylor \& Francis Group, Volume 60(2), pp.87-93. Available online 
also at: $\underline{\text { https://doi.org/10.1080/104598 }}$

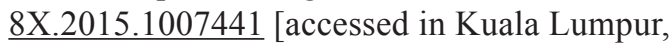
Malaysia: 3 August 2019].

Christie, B., S. Beames \& P. Higgins. (2016). "Context, Culture, and Critical Thinking: Scottish Secondary School Teachers' and Pupils' Experiences of Outdoor Learning" in British Educational Research Journal, Volume 42(3), pp.417-437. Available online also at: https:// doi.org/10.1002/berj.3213 [accessed in Kuala Lumpur, Malaysia: 3 August 2019].

Clarke-Vivier, S. \& J.C. Lee. (2018). "Because Life Doesn't Just Happen in a Classroom on the Benefits of, and Obstacles to, Out-of-School Learning Utilizing Field Trips as a Vehicle to Improve Student Outcomes" in Journal of Experiential Education, Volume 27(2).

Daga, Agustinus Tanggu. (2020). "Perbandingan Pendidikan Karakter dalam Kurikulum Sekolah Dasar di Malaysia, India, dan Indonesia" dalam JES: Jurnal Edukasi Sumba, Volume 4(1), ms.23-30.

Dewey, John. (1897). "My Pedagogic Creed" in School Journal, Volume 54(3), pp.77-80.

Eroshkin, S.Y. et al. (2017). "The Paradigm of the Integration of Different Types of Management Information Systems in Investment and Construction Company Implementing the Project Approach" in PROCEDIA: Computer Science, Volume 103 [October], pp.605-608. Available online also at: https://doi.org/10.1016/j. procs.2017.01.076 [accessed in Kuala Lumpur, Malaysia: 3 August 2019].

Feille, K.K. (2017). "Teaching in the Field: What Teacher Professional Life Histories Tell about How They Learn to Teach in the Outdoor Learning Environment" in Research in Science Education, Volume 47(3), pp.603-620. Available online also at: https://doi.org/10.1007/s11165016-9519-9 [accessed in Kuala Lumpur, Malaysia: 3 August 2019].

Gay, L.R. \& P. Airasian. (2003). Education Research: Competencies for Analysis. London: Merrill Publishing, seventh edition.

Govindarajoo, Shanila A/P. (2018). "Pengajaran dan Pembelajaran Kemahiran Berfikir Aras Tinggi dalam Sains : Kesediaan Guru dan Isu-isunya”. Wujud secara online di: https://icge.unespadang. ac.id/asset/file/files/icge\%20IV/II/Untitled 45. pdf [dilayari di Kuala Lumpur, Malaysia: $\overline{17} \mathrm{hb}$ Ogos 2019].

Habidin, Nurul Fadly et al. (2019). Amalan Terbaik dalam Penambahbaikan Sistem Pendidikan: Pengajaran dan Penyelidikan. Tanjong Malim: Kaizentrenovation, Sdn Bhd. Wujud secara online pula di: https://umexpert.um.edu.my/public view. php?type $=$ publication $\&$ row $=$ ODU $5 \mathrm{Mzg} \%$ 3D [dilayari di Kuala Lumpur, Malaysia: $24 \mathrm{hb}$ Februari 2020].

Halim, Paezah Abd \& Faridah Yunus. (2017). "Kepentingan Penglibatan Ibu Bapa dalam Aktiviti Pembelajaran Kanak-kanak di PraSekolah”. Kertas Kerja Tidak Diterbitkan. Bangi: UKM [Universiti Kebangsaan Malaysia]. Wujud secara online pula di: http://conference.kuis.edu. my/pasak2017/images/prosiding/pendidikan/14PAEZAH-ABD-HALIM.pdf [dilayari di Kuala Lumpur, Malaysia: 24hb Ogos 2019].

Hamzah, A. (2010). Kaedah Kualitatif dalam Penyelidikan Sosio-Budaya" dalam Jurnal Pengajian Media Malaysia, Volume 6(1).

Hasnan, Harits Asyraf. (2020). "Usaha Malaysia dalam Menangani Pandemik Covid-19" dalam ASTRO AWANI, pada 5hb April. Wujud secara online pula di: https://www.astroawani. com/berita-malaysia/usaha-malaysia-dalammenangani-pandemik-covid19-236795 [dilayari di Kuala Lumpur, Malaysia: 17hb Julai 2020].

Hie, Yong Hie et al. (2018). "Peranan Guru sebagai Agen Sosialisasi dalam Membentuk Perpaduan Kaum di Sekolah" dalam AKADEMIKA, Volume 88(2), Julai, ms.95-108. Wujud secara online pula di: https://doi.org/10.17576/akad-20188802-07 [dilayari di Kuala Lumpur, Malaysia: 17hb Ogos 2019].

Horng, J.S. et al. (2005). "Creative Teachers and Creative Teaching Strategies" in International Journal of Consumer Studies, Volume 29(4), July, pp.352-358.

Hua, Ang Kean. (2016). "Pengenalan Rangkakerja Metodologi dalam Kajian Penyelidikan: Satu Kajian Kes" dalam MJSSH: Malaysian Journal of Social Sciences and Humanities, Vol.1, Iss.1 [March], ms.17-23. Wujud secara online pula di: https://media.neliti.com/media/ publications/322466-pengenalan-rangkakerjametodologi-dalam-675009ac.pdf [dilayari di Kuala Lumpur, Malaysia: 17hb Ogos 2019].

Idris, Noraini. (2010). Penyelidikan dalam Pendidikan. Kuala Lumpur: McGraw-Hill (M), Sdn Bhd.

Ismail, W.A. Wan et al. (2016). "Kesediaan Guru Pendidikan Islam Sekolah Rendah di Selangor terhadap Penerapan KBAT dalam Pengajaran dan Pembelajaran" dalam Journal of Advanced Research in Applied Sciences and Engineering Technology, Vol.3, No.1, ms.79-92. Wujud secara online pula di: http://www.akademiabaru.com/ doc/ARSBSV3 N1 P79 92.pdf [dilayari di Kuala Lumpur, Malaysia: 24hb Ogos 2019].

Isnen, Mohd Suhaimin. (2019). "26 Perkara Baharu dalam Sistem Pendidikan Malaysia”. Wujud 
secara online pula di: http://www.cikgusuhaimin. com/2019/10/23-perkara-baharu-dalam-sistem. html [dilayari di Kuala Lumpur, Malaysia: $10 \mathrm{hb}$ Februari 2020].

Jamaludin, Muhamad Hanapi. (2020). "Covid-19: Apa di Sebalik Angka?" dalam MD: Malaysia Dateline, pada $12 \mathrm{hb}$ April. Wujud secara online pula di: https://malaysiadateline.com/covid-19apa-di-sebalik-angka/ [dilayari di Kuala Lumpur, Malaysia: 22hb Jun 2020].

Johari, Faridah Mariani binti et al. (2014). "Isu dan Cabaran Pelaksanaan Pendidikan Asas Vokasional (PAV) di Sekolah Menengah Harian, Malaysia" dalam PDE: Professional Development in Education. Wujud secara online pula di: http://simpen.lppm.ut.ac.id/ Internasional\%20Seminar [dilayari di Kuala Lumpur, Malaysia: $31 \mathrm{hb}$ Ogos 2019].

"Jumlah Kes COVID-19 di Setiap Negeri di Malaysia". Wujud secara online pula di: http:// covid-19.moh.gov.my/ [dilayari di Kuala Lumpur, Malaysia: 17hb Julai 2020].

KPM [Kementerian Pendidikan Malaysia]. (1996). Akta Pendidikan. Kuala Lumpur: Percetakan Nasional Malaysia Bhd.

KPM [Kementerian Pendidikan Malaysia]. (2016a). Buku Penerangan KSSM. Putrajaya: Bahagian Pembangunan Kurikulum.

KPM [Kementerian Pendidikan Malaysia]. (2016b). Surat Pekeliling Ikhtisas Kementerian Pendidikan Malaysia Bilangan 9 Tahun 2016. Putrajaya: Bahagian Pembangunan Kurikulum.

KPM [Kementerian Pendidikan Malaysia]. (2017). Dokumen Standard Kurikulum dan Pentaksiran. Putrajaya: Bahagian Pembangunan Kurikulum.

Kvamme, Ole Andreas. (2017). "The Significance of Context : Moral Education and Religious Education Facing the Challenge of Sustainability" in Discourse and Communication for Sustainable Education, Volume 8(2), pp.24-38. Available online also at: https://doi.org/10.1515/dcse-2017$\underline{0013}$ [accessed in Kuala Lumpur, Malaysia: 3 August 2019].

Leach, N. (2018). "Impactful Learning Environments: A Humanistic Approach to Fostering Adolescents' Post-Industrial Social Skills" in Journal of Humanistic Psychology, pp.1-20.

Lee, Nasha \& Benjamin Ong. (2020). “Covid-19: 3 Lessons for Climate Change" in United Nations Development Programme. Available online also at: https://www.my.undp.org/content/malaysia/ en/home/stories/covid-19--3-lessons-forclimate-change.html [accessed in Kuala Lumpur, Malaysia: 20 May 2020].

Lloyd, A., S. Truong \& T. Gray. (2018). "Place-
Based Outdoor Learning: More than a Drag and Drop Approach" in Journal of Outdoor and Environmental Education, Volume 21(1), pp.45-60. Available online also at: https://doi. org/10.1007/s42322-017-0002-5 [accessed in Kuala Lumpur, Malaysia: 3 August 2019].

Mahmood, H. (2014). "Civics and Citizenship Education in Malaysia: The Voice of Micro Policy Enactors". Unpublished Doctoral Dissertation. UK [United Kingdom]: Cardiff University.

Mankiw, S., J. Strasser \& L.M. Bresson. (2018). A Natural Choice: Learning Outdoors. USA [United Sates of America]: National Association for the Education of Young Children.

Mcgowan, A.L. (2016). "Impact of One-Semester Outdoor Education Programs on Adolescent Perceptions" in Journal of Experiential Education. Available online also at: https://doi. org/10.1177/1053825916668902 [accessed in Kuala Lumpur, Malaysia: 3 August 2019].

Morris, M. \& L.O. Donnell. (2005). "Engaging and Learning with the Outdoors: The Final Report of the Outdoor Classroom in a Rural Context Action Research Project" in National Foundation for Educational Research.

Musa, Khalip \& Hariza Abd Halim. (2015). "Kemahiran Interpersonal Guru dan Hubungan dengan Pencapaian Akademik Pelajar" dalam Jurnal Pendidikan Malaysia, Volume 40(2), ms.89-99.

Nelliani. (2020). "Pandemi, Pembelajaran Digital, dan Ancaman Moralitas" dalam AJNN: Aceh Journal of National Network.

Neuman, W.L. (2006). Social Research Methods: Qualitative and Quantitative Approaches. Toronto: Pearson.

Othman, Norzila. (2020). "Hikmah PKP: Bila Alam Berbicara melalui Kualiti Udara dan Air”. Wujud secara online pula di: https://news.uthm.edu.my/ ms/2020/05/hikmah-pkp-bila-alam-berbicaramelalui-kualiti-udara-dan-air/ [dilayari di Kuala Lumpur, Malaysia: 17hb Julai 2020].

Putra, Armansyah. (2017). "Mengkaji \& Membandingkan Kurikulum 7 Negara: Malaysia, Singapura, Cina, Korea, Jepang, Amerika, dan Finlandia”. Kertas Kerja Tidak Diterbitkan. Sumbawa Besar, Indonesia: Universiti Samawa.

Rahimah, Haji. (2015). "Educational Development and Reformation in Malaysia: Past, Present, and Future" in Journal of Educational Administration, Volume 36(5), February. Wujud secara online pula di: https://doi.org/10.1108/09578239810238456 [dilayari di Kuala Lumpur, Malaysia: 3 Ogos 2019].

Rawleigh, M., H. Kemp \& M. Asfeldt. (2019). "We are Wilderness Explorers: A Review of Outdoor Education in Canada" in Journal of Experiential 
Education. Available online also at: https://doi. org/10.1177/1053825919865574 [accessed in Kuala Lumpur, Malaysia: 13 January 2020].

Rogers, Carl R. (1951). "Studies in Client-Centered Psychotherapy III: The Case of Mrs. Oak - A Research Analysis" in Psychological Service Center Journal.

Shufiyati, Efta. (2016). "PKN di Malaysia". Wujud secara online di: https://eftashufiyati.wordpress. com/2016/12/10/pkn-di-malaysia/ [dilayari di Kuala Lumpur, Malaysia: 17hb Ogos 2019].

Sidiq, Umar, Moh Miftachul Choiri \& Anwar Mujahidin. (2019). Metode Penelitian Kualitatif di Bidang Pendidikan. Ponorogo, Jawa Timur, Indonesia: Penerbit CV Nata Karya. Wujud secara online pula di: http://repository.iainponorogo. ac.id/484/1/METODE [dilayari di Kuala Lumpur, Malaysia: 10hb Februari 2020].

Sultoni, Achmad. (2016). "Pendidikan Karakter dan Kemajuan Negara: Studi Perbandingan Lintas Negara" dalam JOIES: Journal of Islamic Education Studies, Vol.1, No.1 [Juni], ms.184-207.

Sumintono, Bambang, Lokman Mohd Tahir \& Mohd Anuar Abdul Rahman. (2012). "Pendidikan Moral di Malaysia: Tantangan dan Implementasi Pendidikan Karakter di Sekolah" dalam Jurnal Pendidikan Karakter, Thn.II, No.1 [Februari], ms.14-22.

Ta'rifin, Ahmad. (2009). "Membangun Interaksi Humanistik dalam Proses Pembelajaran" dalam Forum Tarbiyah, Vol.7, No.1 [Juni], ms.99-114.

Tatang, Dede. (2018). "Pentingnya Mengajak Anak Belajar di Luar Kelas" dalam KOMPASIANA: Beyond Blogging, pada $28 \mathrm{hb}$ Ogos. Wujud secara online pula di: https://www.kompasiana.com/ karbox/5b84924b6ddcae068a552973/peranpenting-pembelajaran-di-luar-kelas-terhadapprestasi-siswa [dilayari di Kuala Lumpur, Malaysia: 24hb Ogos 2019].

Temu bual dengan Responden A, seorang Guru Pendidikan Moral yang mengajar murid Tingkatan I Sekolah Menengah, di Kuala Lumpur, Malaysia, pada 9hb Oktober 2019.

Temu bual dengan Responden B, seorang Guru Pendidikan Moral yang mengajar murid Tingkatan I Sekolah Menengah, di Kuala Lumpur, Malaysia, pada 9hb Oktober 2019.

Temu bual dengan Responden C, seorang Guru Pendidikan Moral yang mengajar murid Tingkatan II Sekolah Menengah, di Kuala Lumpur, Malaysia, pada 17hb Oktober 2019.

Temu bual dengan Responden D, seorang Guru Pendidikan Moral yang mengajar murid Tingkatan II Sekolah Menengah, di Kuala Lumpur, Malaysia, pada 17hb Oktober 2019.

Temu bual dengan Responden E, seorang Guru
Pendidikan Moral yang mengajar murid Tingkatan III Sekolah Menengah, di Kuala Lumpur, Malaysia, pada 24hb Oktober 2019.

Temu bual dengan Responden F, seorang Guru Pendidikan Moral yang mengajar murid Tingkatan III Sekolah Menengah, di Kuala Lumpur, Malaysia, pada 24hb Oktober 2019.

Temu bual dengan Responden G, seorang Guru Pendidikan Moral yang mengajar murid Tingkatan III Sekolah Menengah, di Kuala Lumpur, Malaysia, pada 24hb Oktober 2019.

Teoh, Ming. (2020). "Blue Skies, Less Waste: Covid-19 and the MCO's Effects on the Enviroment" in newspaper of The Star. Available online also at: https://www.thestar.com.my/ lifestyle/living/2020/04/22/earth-day-a-wake-upcall-to-lead-more-environmentally-sustainablelives [accessed in Kuala Lumpur, Malaysia: 20 May 2020].

Terence, L. \& D. Kerry. (2018). "Testing and Measuring the Impact of Character Education on the Learning Environment and its Outcomes" in Journal of Character Education, Volume 14(2), pp.1-22.

Thorburn, M. \& P. Allison. (2017). "Learning Outdoors and Living Well? Conceptual Prospects for Enhancing Curriculum Planning and Pedagogical Practices" in Cambridge Journal of Education, Volume 47(1), pp.103-115. Available online also at: https://doi.org/10.1080/030576 4X.2015.1118438 [accessed in Kuala Lumpur, Malaysia: 3 August 2019].

Torkos, H. (2019). "Positive Attitude Buildout at Second Grades through Outdoor Education Activities" in Journal Plus Education, Volume XXIII, pp.11-18.

Vijayaletcmy, M. \& N. Selvam. (2015). "Pengajaran \& Pembelajaran Kemahiran Berfikir Aras Tinggi Sekolah Menengah: Tinjauan terhadap Tahap Pengetahuan Guru-guru tentang KBAT dan Pelaksanaannya". Kertas Kerja dibentang dan dibincang dalam Seminar Penyelidikan Pendidikan Kebangsaan, ms.352-360. Wujud secara online pula di: http://ipgkik.com/v2/wpcontent/uploads/2015/08/A1_Artikel-Penuh-pdfSPPK2015 09072015-1-1.pdf [dilayari di Kuala Lumpur, Malaysia: 17hb Ogos 2019].

WB [World Bank]. (2020). "East Asia and Pacific in the Time of COVID-19" in East Asia and Pacific Economic Update (April). Washington, DC: World Bank, DOI:10.1596/978-1-4648-1565-2.

Yin, Khoo Yin. (2008). “Keberkesanan Kaedah Penyelesaian Masalah secara Kolaboratif dalam Kalangan Pelajar Ekonomi Tingkatan Enam”. Tesis Ph.D. Tidak Diterbitkan. Kuala Lumpur: FP UM [Fakulti Pendidikan, Universiti Malaya]. 